\title{
The Performance of Synapses That Convey Discrete Graded Potentials in an Insect Visual Pathway
}

\author{
Peter J. Simmons \\ Department of Neurobiology, University of Newcastle upon Tyne, Newcastle upon Tyne NE2 4HH, United Kingdom
}

Synapses from nonspiking neurons transmit small graded changes in potential, but variability in their postsynaptic potential amplitudes has not been extensively studied. At synapses where the presynaptic signal is an all-or-none spike, the probabilistic manner of neurotransmitter release causes variation in the amplitudes of postsynaptic potentials. I have measured the reliability of the operation of synapses that convey small graded potentials between pairs of identified large, second-order neurons in the locust ocellar system. IPSPs are mediated by small rebound spikes, which are graded in amplitude, in the presynaptic neuron. A transfer curve plotting amplitudes of spikes against amplitudes of IPSPs has a characteristic $S$ shape with a linear central portion where IPSP amplitude is between -0.2 and -0.6 as large as spike amplitude but shows appreciable scatter. Approximately half of the scatter is attributable to back- ground noise, most of which originates in photoreceptors and persists in darkness. The remaining noise is intrinsic to the synapse itself and is usually $0.3-0.7 \mathrm{mV}$ in amplitude. It limits the resolution with which two spike amplitudes can be distinguished from one another to $\sim 2 \mathrm{mV}$ and, because the linear part of the transfer curve occupies $\sim 10 \mathrm{mV}$ in spike amplitudes, limits the number of discrete signal levels that can be conveyed across the synapse to approximately five. The amplitude of the noise is constant throughout the synaptic operating range, which means it is unlikely that presynaptic membrane potential controls transmitter release by setting a single probability level for quantal release.

Key words: synapse; resolution; noise; locust; ocellus; transfer curve
At chemical synapses, the rate at which neurotransmitter is released is regulated by the membrane potential of the presynaptic neuron. The graded relationship between presynaptic and postsynaptic potentials is normally obscured in spiking neurons where it was first established (Katz and Miledi, 1967) but enables nonspiking neurons to transmit small changes in membrane potential to their postsynaptic targets. Neurons that use graded potentials avoid a time-consuming spike frequency code, and nonspiking neurons in the outer layers of the fly compound eye can carry 2000 bits/sec (de Ruyter and Laughlin, 1996), five times more than spiking neurons (Theunissen et al., 1996; Rieke et al., 1997). However, noise introduced during synaptic transmission is likely to limit the amount of information carried by graded potentials. Noise in output synapses from photoreceptors significantly degrades the resolution with which higher-order neurons encode information about changes in light intensity both in vertebrates (Ashmore and Copenhagen, 1983) and invertebrates (Laughlin et al., 1987). A major source of noise is the probabilistic manner with which quanta of neurotransmitter are released. This has been almost exclusively studied at synapses where the presynaptic signal is an all-or-none spike. Although at neuromuscular junctions several hundred quanta are released for each presynaptic spike (del Castillo and Katz, 1954; Boyd and Martin, 1956; Johnson and Wernig, 1971), in CNSs the number of quanta

\footnotetext{
Received July 15, 1999; revised Sept. 20, 1999; accepted Sept. 23, 1999.

This work was supported by Biotechnology and Biological Sciences Research Council (UK) Grant 13/S06923. Thanks to Gerd Leitinger and Claire Rind for helpful comments and for reading this manuscript and to Rob de Ruyter van Steveninck and David Walshaw for advice on statistics.

Correspondence should be addressed to Dr. Peter J. Simmons, Department of Neurobiology, University of Newcastle upon Tyne, Newcastle upon Tyne NE2 4HH, UK. E-mail: p.j.simmons@ncl.ac.uk.

Copyright (C) 1999 Society for Neuroscience 0270-6474/99/1910584-11\$05.00/0
}

released per spike is often so small that postsynaptic potential amplitude varies considerably (Kuno, 1964; Korn et al., 1982; Laurent and Sivaramakrishnan, 1992; Gulyás et al., 1993). Transfer curves for a number of synapses that convey graded potential have been plotted (Burrows and Siegler, 1978; Blight and Llinás, 1980; Angstadt and Calabrese, 1991; Manor et al., 1997) but without measurements of variability in postsynaptic potential amplitude.

The aim of this work is to measure variability in transmission across a synapse that transmits graded potentials in the locust ocellar visual system. Seven large L-neurons (Goodman, 1976) convey graded signals about variations in light from each lateral ocellar retina to the brain (Patterson and Goodman, 1974; Wilson, 1978b). The large space constants of L-neurons (Wilson, 1978b; Ammermüller, 1986) means that signals decrement little in traveling between presynaptic or postsynaptic sites and a recording electrode. L1-3 make excitatory synapses that transmit tonically both onward to large third-order neurons (Simmons, 1981), which are involved in flight stabilization (Simmons, 1980; Rowell and Reichert, 1986) and laterally to L4-5 (Simmons, 1982). Each L1-3 also makes, with both its sister neurons, inhibitory synapses that transmit phasically, usually after a presynaptic spike (Simmons, 1982, 1985). These spikes are produced when light intensity falls rapidly (Patterson and Goodman, 1974; Wilson, 1978a) and are rebound responses to the end of a hyperpolarizing potential (Wilson, 1978b). By collecting large numbers of measurements to construct synaptic transfer curves, I show here that unreliability in synaptic transmission is a major cause of variability in postsynaptic potential amplitude and limits the smallest size of change in presynaptic potential that can be transmitted faithfully across the synapse. 

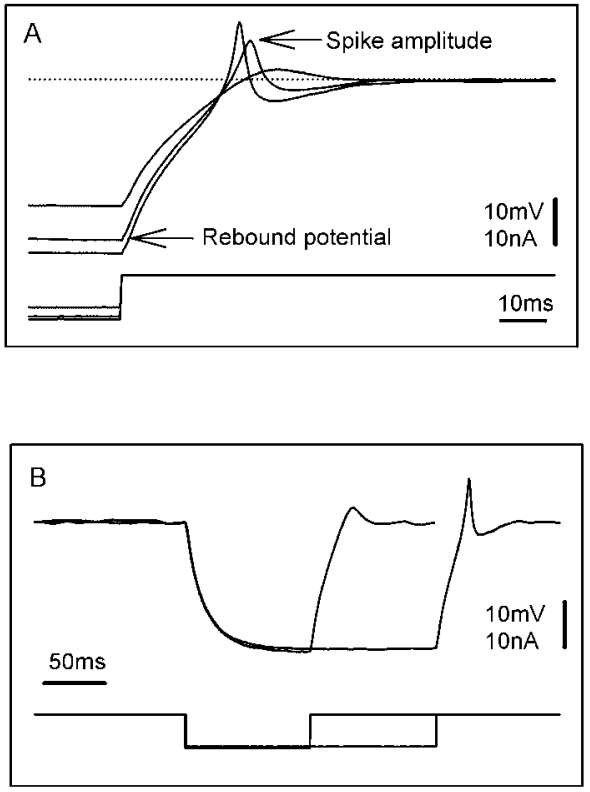
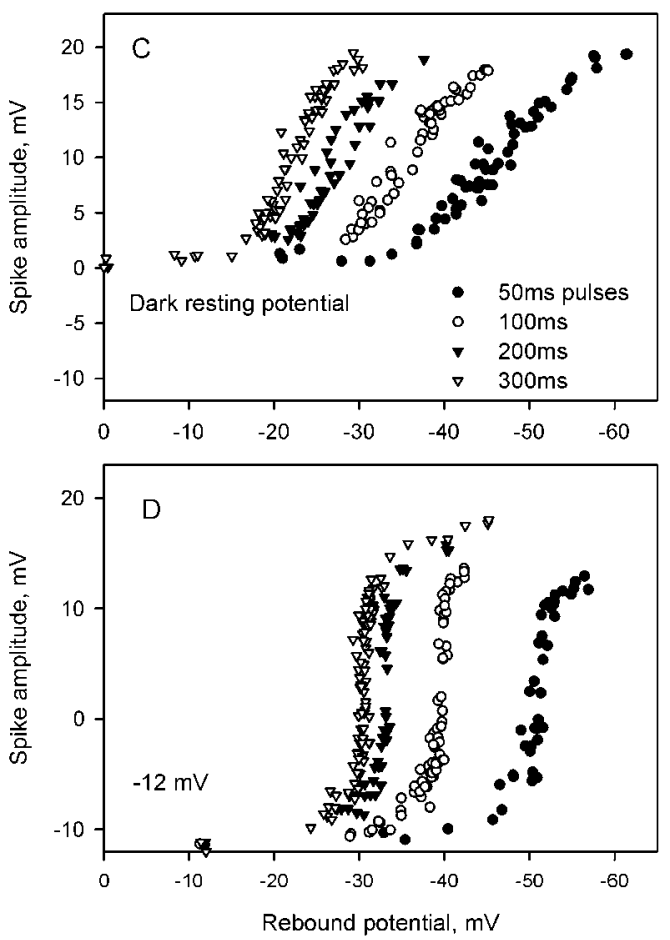

Figure 1. Properties of spikes in L-neurons. A, Intracellular recordings of spikes (top traces) rebounding from the end of 300-msec-long pulses of hyperpolarizing current (bottom traces) of three different amplitudes. The dotted line indicates dark resting potential, and arrows indicate for one rebound spike how rebound potential and spike amplitude were measured relative to dark resting potential. $B$, Responses to $7 \mathrm{nA}$ hyperpolarizing current pulses, 100 and $200 \mathrm{msec}$ long. $C, D$, Graphs of spike amplitude against rebound potential. Measurements in $C$ were made in darkness and in $D$ in steady light, which hyperpolarized the L-neuron by $12 \mathrm{mV}$ relative to its dark resting potential.

\section{MATERIALS AND METHODS}

Experiments were conducted on 84 adult male and female Schistocerca gregaria, obtained from our own breeding colony or by purchase from commercial suppliers. The results presented in this paper were obtained from 56 preparations in which stable recordings were made from pairs of L-neurons connected by inhibitory synapses. The dorsal surface of the brain and lateral ocellar nerves were exposed, and the mandibular muscles were dissected away before the head was removed from the animal, taking care to maintain the tracheal supply to the brain intact. Pins fastened the head to a wax-covered dish, which was filled with $\sim 1.2$ $\mathrm{ml}$ of saline to just cover the ocellar nerves. To reduce synaptic transmission from photoreceptors to L-neurons in some preparations, the neurilemma around a lateral ocellus was gently torn using two pairs of sharpened watchmakers forceps. A $1 \%$ w/v solution of Sigma (St. Louis, MO) Protease Type XIV in saline was applied to the surface of the brain for $3 \mathrm{~min}$ to facilitate penetration of the neurilemma by microelectrodes. The preparation was placed in a black box, and recordings were made in complete darkness unless otherwise indicated, where light from an ultrabright green light-emitting diode (Radio Spares) was directed at the ocellus.

Intracellular recordings were made with glass microelectrodes filled with $2 \mathrm{M}$ potassium acetate, DC resistances 40-60 M , connected to an Axoclamp 2-A or 2B amplifier (Axon Instruments, Foster City, CA) operated in the bridge balance mode. Recordings were made from the axons of L-neurons in either a lateral ocellar nerve or tract. Penetration of an L-neuron was registered by brisk responses to dim 0.1 -sec-long pulses of light from the light-emitting diode, with background synaptic noise between stimuli. A synaptic connection between a pair of L-neurons was sought by eliciting rebound spikes in one of the pair with pulses of negative current. Current pulses to elicit rebound spikes were injected at a rate of one every $2 \mathrm{sec}$, which is sufficient to allow recovery of a synapse after production of an IPSP (Simmons, 1985). Because of this relatively low rate of stimulation, it was necessary to maintain stable intracellular recordings for at least $15 \mathrm{~min}$ to collect sufficient data for analysis, and a few recordings remained stable for $>1 \mathrm{hr}$. A number of checks were made to ensure the quality of recordings was maintained, including stability of resting potential, level of background noise, synaptic gain, and maximum IPSP size.
Intracellular recordings were collected onto computer using a 1401 interface and Spike2 Software (Cambridge Electronic Design, Cambridge, UK). Some analysis was performed on-line, which helped assess recording quality. Subsequently, measurements of membrane potentials and event durations were made using Spike2 software, and data were analyzed using SigmaPlot and SigmaStat (SPSS, Chicago, IL). In many experiments, the linear section of a synaptic transfer curve was analyzed by finding the regression line that provided the best fit between the amplitudes of presynaptic spikes and postsynaptic IPSPs. Variation in IPSP amplitude was expressed as the SD of the IPSP residuals about this line. The normality of distributions was tested using the KolmogorovSmirnov test, which gives values for the cumulative squared departure of data points from a normal distribution [the Kolmogorov-Smirnov distance (K-Sd)] and for the probability that data are normally distributed (a value of $\geq 0.05$ is usually taken to indicate that data are taken from a normally distributed population).

\section{RESULTS}

\section{Graded spikes in L-neurons}

After the end of a hyperpolarizing potential, the membrane potential of an L-neuron overshoots resting potential to generate a small rebound spike (Wilson, 1978b), which enhances responses to sudden decreases in illumination and is required for transmission at inhibitory synapses between L-neurons (Simmons, 1982, 1985). Similar regenerative responses occur in lamina cells of the arthropod compound eye (Zettler and Järvilehto, 1973), nonspiking stretch receptors in crab legs (Blight and Llinás, 1980), and, to a smaller extent, local nonspiking interneurons in locust thoracic ganglia (Laurent, 1990). Stimulus parameters that influence spike amplitude have not been described before, although there is evidence that the voltage-sensitive conductances responsible for L-neuron spikes are mostly inactivated at dark resting potential (Ammermüller and Zettler, 1986). Spike amplitude in L-neurons depends on both the amplitude (Fig. 1A) and duration (Fig, 1B) 
A

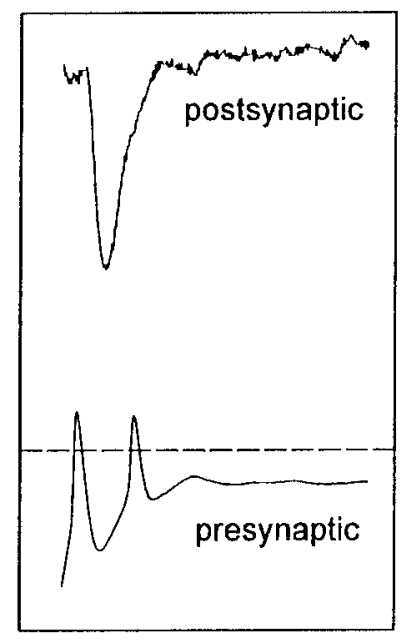

B

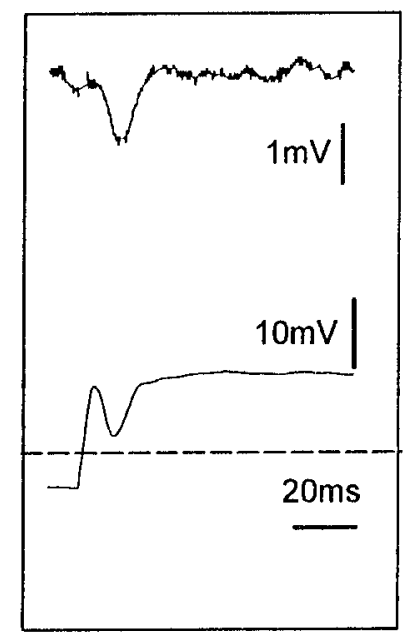

Figure 2. IPSPs in one L-neuron elicited by depolarizing potentials in another L-neuron. $A$, IPSP (top trace) mediated by a rebound spike (bottom trace) produced at the end of a pulse of hyperpolarizing current injected into the presynaptic neuron. $B$, A pulse of depolarizing current injected into the presynaptic neuron elicited a spike followed by a more prolonged depolarizing potential and a short-lasting IPSP in the postsynaptic neuron. Current pulses were added to a steady DC current injected to hyperpolarize the presynaptic neuron from its dark resting potential (dashed lines). In this experiment, separate electrodes were used to inject current, to record presynaptic potential, and to record postsynaptic potential.

of the hyperpolarizing potential from which the neuron rebounds (the "rebound potential"). For hyperpolarizing pulses of a particular duration, there is an S-shaped relationship between the amplitude of the rebound potential and the amplitude of the spike (Fig. 1C,D). The effects of increasing pulse duration, up to 300 msec, were to shift curves toward smaller values of rebound potential and to increase their gradients. Over the linear parts of the curves in Figure $1 C$, each $1 \mathrm{mV}$ change in rebound potential caused an increase in spike amplitude of $0.82 \mathrm{mV}$ for 50 -mseclong pulses and of $1.76 \mathrm{mV}$ for 300 -msec-long pulses (SDs of spike amplitude residuals, $\pm 1.21 \mathrm{mV}$ for $50 \mathrm{msec}$ pulses and $\pm 1.17 \mathrm{mV}$ for $300 \mathrm{msec}$ pulses). When an L-neuron was held steadily hyperpolarized from its dark resting potential (approximately $-40 \mathrm{mV}$; Simmons, 1985; Ammermüller and Zettler, 1986), the family of curves of rebound potential plotted against spike amplitude became steeper, so that the spikes increasingly become all-or-none events, and peak spike amplitude reduced slightly (Fig. 1D). In these experiments, separate electrodes were used to inject current and record potential. Spike amplitude recorded through the two electrodes was the same, which means that, in later experiments, rebound spike amplitude could be measured reliably using a single electrode attached to an amplifier operated in the bridge balance mode.

\section{IPSPs and background noise in L-neurons}

Transmission can only be sustained for short times at inhibitory synapses between L-neurons: IPSPs mediated by rebound spikes (Fig. $2 A$ ) have durations similar to those elicited by longer-lasting depolarizing potentials (Fig. $2 B$ ). The two IPSPs had the same rise time $(6.5 \mathrm{msec})$ but different amplitudes, because there is an extremely limited time window in which the IPSP can be generated (Simmons, 1985), and the presynaptic potential rose slightly
A

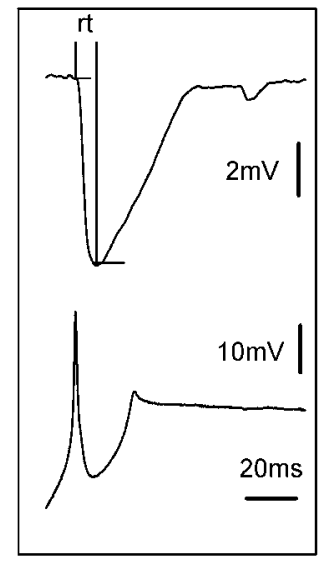

B

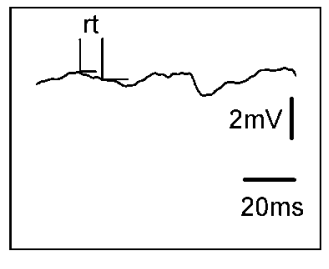

C

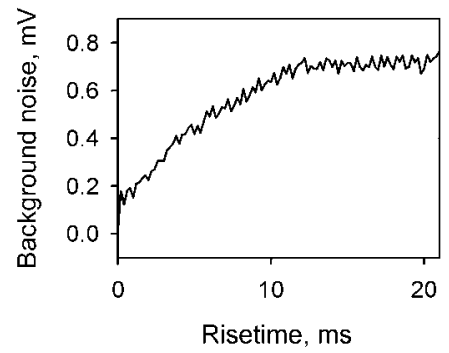

Figure 3. IPSPs and background noise in an L-neuron. $A$, Rebound spike (bottom trace) in one L-neuron and IPSP in a second (top trace). Besides the amplitude, the rise time $(r t)$ of the IPSP was measured. $B$, Background noise was measured starting $1 \mathrm{sec}$ after each IPSP as the potential difference occurring during an interval equal to the rise time of the IPSP. $C$, Measured in this way, background noise varies with IPSP rise time.

more slowly in Figure $2 B$ than in Figure $2 A$ (2.5 vs 10.5 $\mathrm{mV} / \mathrm{msec}$ ).

In three different experiments, the reversal potentials of maximum-amplitude IPSPs were measured. Different amplitudes of hyperpolarizing current were injected through one electrode into the postsynaptic neuron, whereas a second electrode recorded potential changes, and IPSP reversal potential was measured from a regression of IPSP amplitude against L-neuron potential. The values measured were $-35,-37$, and $-42 \mathrm{mV}$ relative to dark resting potential, which are several times greater than the maximum amplitudes of IPSPs recorded so that IPSP amplitude is not limited by its reversal potential.

IPSPs were superimposed on background noise, which persisted in complete darkness and often consisted of discrete hyperpolarizing potentials, such as the one that followed the IPSP in Figure $3 A$. Each IPSP measurement was paired with a measurement of background noise (Fig. $3 A, B$ ), which was taken as the difference in postsynaptic potential at $1 \mathrm{sec}$ after the presynaptic spike and at a time equal to IPSP rise time afterward. Background noise would vary with IPSP rise time, as shown in Figure $3 C$, but, except for the smallest IPSPs, rise time was constant for each connection and was usually between 6.5 and 8 msec. Photoreceptors are likely to be the major source of background noise in L-neurons. Wilson (1978c) showed that hyperpolarizing potentials recorded from L-neurons in darkness are likely to arise from photoreceptors, and the background noise recorded in this study decreased in amplitude when an L-neuron was hyperpolarized toward -35 to $-40 \mathrm{mV}$ from dark resting potential, showing that it was probably composed of inhibitory postsynaptic activity. Although the rate of spontaneous bump production by a locust compound eye photoreceptor is as low as one every 10 min (Lillywhite, 1977), several hundred photoreceptors can converge onto each L-neuron (Goodman et al., 1979). 
A

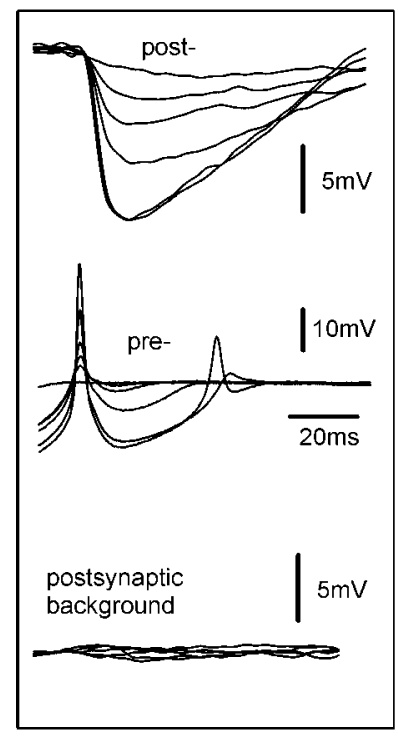

B

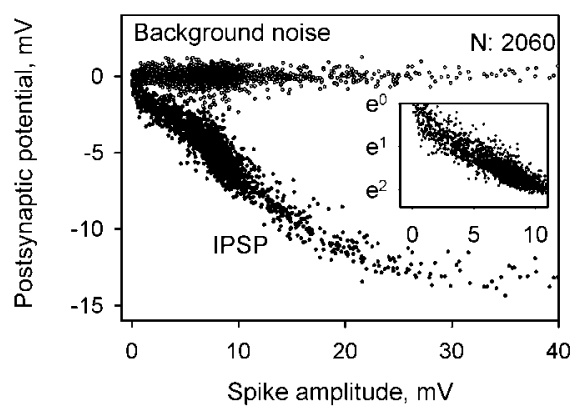

C

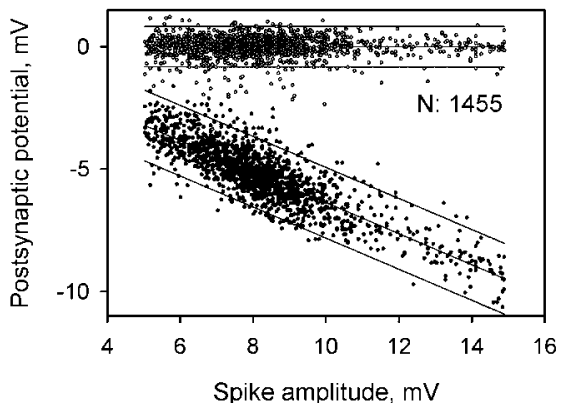

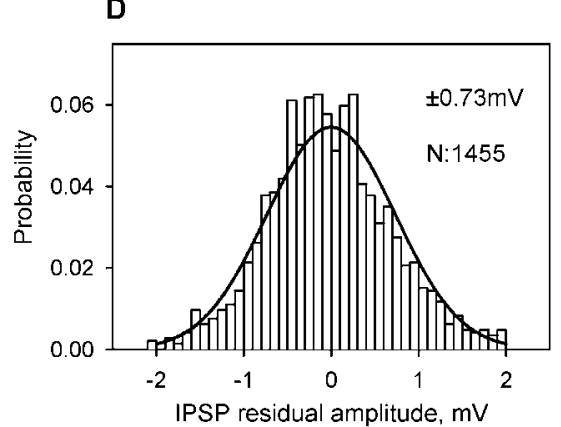

E

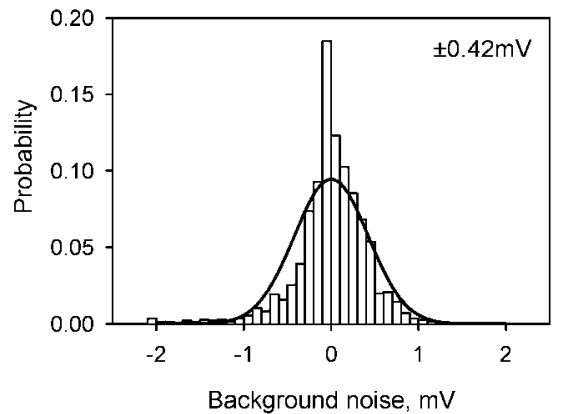

Figure 4. Transmission at an inhibitory synapse between two L-neurons. A, Overlaid recordings of six IPSPs (top traces) in response to rebound spikes of different amplitudes (middle traces). The background noise recorded $1 \mathrm{sec}$ after each IPSP is shown on the bottom traces. B, Plot of IPSP amplitude against presynaptic spike amplitude for 2060 IPSPs measured over $100 \mathrm{~min}$. A measurement of background noise accompanied each IPSP recorded. Inset, Plot of spike amplitude against the natural logarithm of IPSP absolute amplitude for the lower part of the transfer curve. $C$, Data for the linear part of the transfer curve in $B$, with regression lines and $95 \%$ prediction intervals. $D$, Distribution of IPSP residuals for the regression line drawn in $C$. The data had an SD of $\pm 0.73 \mathrm{mV}$, and the bell-shaped line is a normal distribution with this SD. E. Distribution of background noise measurements for the data in $C$. The line plots the best-fitting normal distribution for this data ( $\mathrm{SD}, \pm 0.42 \mathrm{mV}$ ).

\section{Transmission at a relatively high-gain inhibitory synapse}

In four preparations, IPSPs $\geq 10 \mathrm{mV}$ in amplitude were recorded, and Figures 4 and 5 show results from one of these in which the recording was sufficiently stable to collect $>2000$ IPSPs. There was a smoothly graded, S-shaped relationship between the amplitudes of spikes and IPSPs (Fig. 4A,B) with considerable scatter in IPSP amplitude for each spike amplitude as well as in background noise. No distinct threshold for transmission is apparent; the smallest IPSP in Figure 4A (top trace) followed a rebound in the presynaptic neuron that failed to give rise to a spike (almost flat trace), and rebounds in presynaptic potential that were too small to trigger spikes consistently caused small IPSPs. The time taken for postsynaptic potential to repolarize after an IPSP decreased with IPSP amplitude, consistent with a shortening of membrane time constant caused by the conductance increase during IPSP production. For spikes up to $10 \mathrm{mV}$ high, there was a good relationship between spike amplitude and the logarithm of IPSP amplitude (Fig. 4B, inset), with a change in spike height of $4.8 \mathrm{mV}$ causing an e-fold change in IPSP height. IPSP amplitude saturated at $-12.5 \mathrm{mV}$, corresponding to a presynaptic spike amplitude of $22 \mathrm{mV}$.

Over the range of spike amplitudes between 5 and $15 \mathrm{mV}$, the relationship between spike and IPSP amplitudes was approximately linear (Fig. 4C), and the best-fitting linear regression had a slope of -0.63 , which is a measure of the gain of the synapse $\left(R^{2}=0.73\right.$; power of test, $\left.\alpha=0.05: 1.00\right)$. Similar curves with scatter almost identical to those in Figure $4, B$ and $C$, were obtained when the rate of presynaptic depolarization was plotted against the maximum rate of postsynaptic hyperpolarization. Scatter in IPSP amplitude about the regression line had an SD of $\pm 0.73 \mathrm{mV}$, with a distribution that was more flat than for a normal distribution (Fig. $4 D$; kurtosis, 0.75 ; K-Sd, $0.04 ; p<0.01$ ). Background noise had an SD of $\pm 0.42 \mathrm{mV}$, and its distribution was more sharply peaked than for a normal distribution (Fig. 4E; kurtosis, 6.3; K-Sd, $0.1 ; p<0.01$ ). The reason for the sharp peak in this distribution is that background noise in the dark is often composed of discrete potentials, and the probability of sampling postsynaptic potential when one of these is not occurring is relatively high.

Inspection of Figure 4B suggests that IPSP variability is similar in different parts of the operating curve for the synapse, and in Figure $4 C$ variance in IPSP amplitude about the regression line for the linear part of the synapse was constant ( $p$ of constant variance $=0.50$ ). To examine IPSP variability in more detail, IPSPs generated by spikes of almost identical amplitude were compared (Fig. 5). In each of the series of overlaid recordings shown in Figure $5 A$, spike amplitude was within 0.02 of 8.29 (left) or 7.90 (right) $\mathrm{mV}$. Because spike amplitude varies from stimulus to stimulus (Fig. $1 C, D$ ), however, very few spikes with amplitudes as close to each other as this were recorded; so IPSPs were gathered into groups where the presynaptic spike varied over a range of $0.2 \mathrm{mV}$ to examine IPSP variability in different regions of the synaptic transfer curve. Each group of IPSPs had an SD between 0.6 and $0.9 \mathrm{mV}$ (Fig. 5B, unshaded histogram bars). The mean of these SDs was $0.73 \mathrm{mV}$, the same as that of the residuals from the regression in Figure $4 D$, and no trend toward larger or smaller deviations was found as spike amplitude increased. Mea- 
A

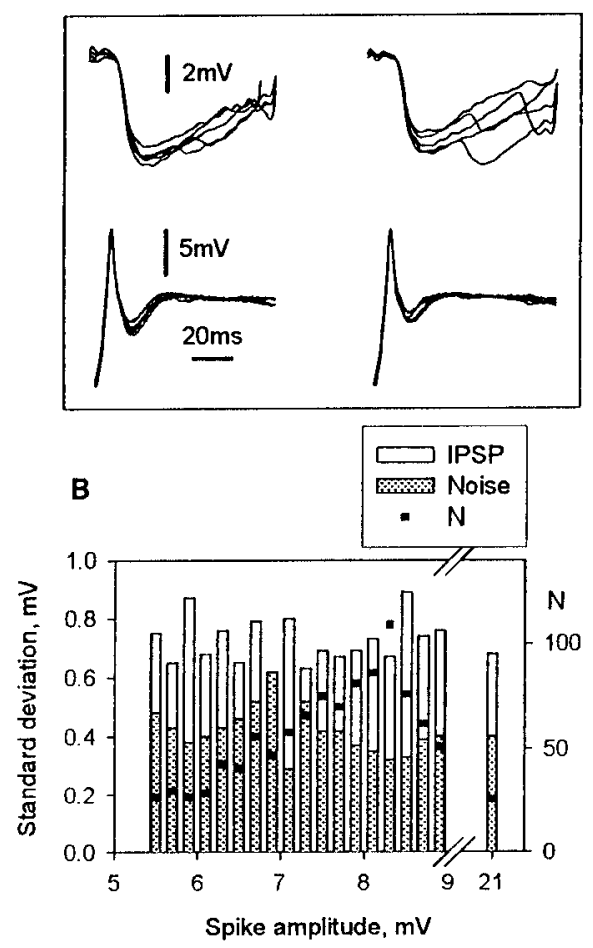

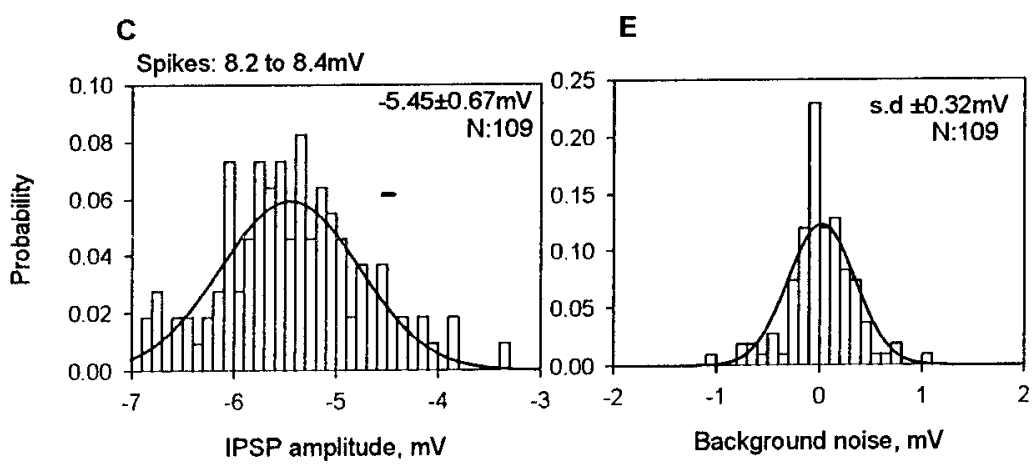

D

Spikes: 7.8 to $8.0 \mathrm{mV}$

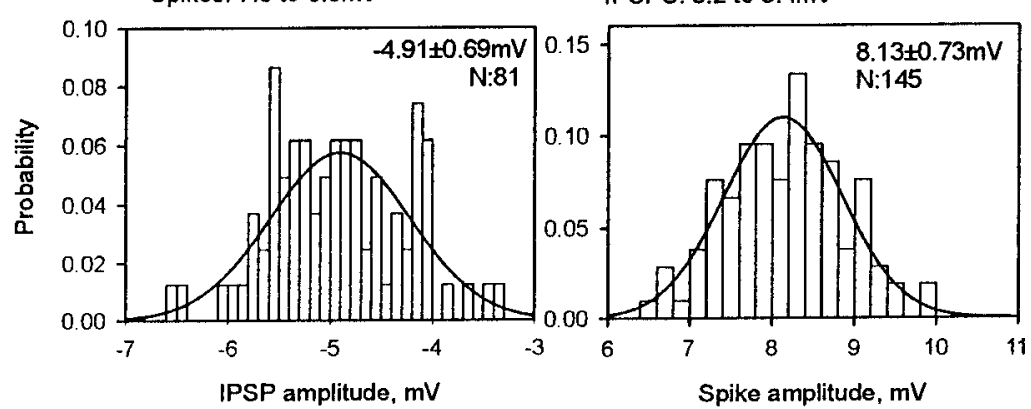

Figure 5. IPSPs mediated by particular amplitudes of presynaptic spikes, from the experiment shown in Figure 4. $A$, Intracellular recordings of five overlaid IPSPs for two different presynaptic spike amplitudes. $B$, Histograms to show IPSP SD and background noise SD for presynaptic spikes of different amplitudes. The number of data points for each presynaptic spike amplitude is given. For spikes up to $9 \mathrm{mV}$ amplitude, data were collected for spikes that varied over a range of amplitudes of $0.2 \mathrm{mV}$; for $21 \mathrm{mV}$ spikes, the spikes varied from 20 to $22 \mathrm{mV}$. C, D, Distribution of IPSP amplitudes for spikes that varied between 8.2 and $8.4 \mathrm{mV}(C)$ or 7.8 and $8.0 \mathrm{mV}(D)$. The mean and SD of IPSP amplitude are given for each histogram, together with the best-fitting normal distribution. The horizontal line in $C$ indicates the range of IPSP amplitudes on the scale of the horizontal axis that would be elicited by a change in spike amplitude of $0.2 \mathrm{mV}$ if the relationship between spike and IPSP amplitudes were linear and noise-free. $E$, Histogram of background noise amplitudes and the best-fitting normal distribution for the IPSP in $C$. F, Distribution of spike amplitudes that mediated IPSPs between 5.2 and $5.4 \mathrm{mV}$ in amplitude, together with the best-fitting normal distribution.

surements of background noise for each group of IPSPs are also plotted in Figure $5 B$ (shaded histogram bars) and varied between 0.3 and $0.6 \mathrm{mV}$ (mean value, $0.42 \mathrm{mV}$ ). For all but one of the IPSP groups, the IPSP SD was greater than the background noise. For IPSPs recorded in the saturated region of the transfer curve, the SDs of IPSP amplitude and background noise were similar to those in the linear part of the transfer curve. This is shown in Figure $5 B$ for IPSPs mediated by spikes $20-22 \mathrm{mV}$ high (histograms on the right; IPSP SD, $\pm 0.68 \mathrm{mV}$; background noise, $\pm 0.40 ; n=26$ ).

Distributions of IPSP amplitude for each $0.2 \mathrm{mV}$ range of spike amplitudes had a ragged appearance, often with several peaks (Figs. 5C,D). The short horizontal line in Fig. 5C indicates the change in IPSP amplitude corresponding to a $0.2 \mathrm{mV}$ change in spike amplitude for this synapse with gain of 0.63 . Each IPSP sample could reasonably be expected to be drawn from a normally distributed distribution (Fig. $5 C$; K-Sd, 0.07; $p=0.26$; Fig. $2 D$; $\mathrm{K}-\mathrm{Sd}, 0.07 ; p=0.34$ ), but samples were consistently flatter than the corresponding normal distribution. Although IPSP amplitude was clustered around peaks that occurred regularly spaced along the IPSP amplitude axis, they could not be fitted well with Poisson or binomial distributions. Also, the locations of peaks in the distributions of IPSPs of neighboring groups did not coincide with each other. For each group of IPSPs, the corresponding background noise was more sharply peaked than a normal distribution and had a negative skew (Fig. 5E). The distribution of spikes which evoked IPSPs within a narrow range of amplitudes $(0.2 \mathrm{mV}$ ) fitted a normal distribution well (Fig. $5 F$; K-Sd, $0.04 ; p=$ $0.79)$ and had SDs between \pm 0.69 and $\pm 1.11 \mathrm{mV}$, with a mean value of $\pm 0.84 \mathrm{mV}$ (10 samples).

Measurements of IPSP SD and background noise SD were used to estimate the contribution of the synapse itself to variation in IPSP amplitude. This was done by subtracting the variance of background noise from the variance of IPSP amplitude (the distributions of IPSP and background amplitudes are close enough to normal for a reasonable estimate to be generated by this method). Throughout the operating range of the synapse, the SD of IPSP amplitude was $\sim 0.73 \mathrm{mV}$, and background noise was $\sim 0.42 \mathrm{mV}$, which means that the SD (square root of variance) of synaptic noise was $0.6 \mathrm{mV}$, approximately one and a half times the SD of background noise.

To estimate the minimum difference in spike amplitudes that can be discriminated at this synapse, the criterion that the mean level of a signal should be separated from that of its neighbors by 2 SDs was adopted. This criterion gives a reliability of $\sim 80 \%$ in distinguishing one signal from another, and this is commonly adopted as a good compromise between reliability and number of signal levels (Snyder et al., 1977). Although IPSP amplitudes were not strictly normally distributed, more complex statistical techniques would have been unlikely to yield improvements in estimates of signal reliability. The SD of IPSP amplitude was, on average, $0.73 \mathrm{mV}$, so two IPSPs could represent two distinct 
A

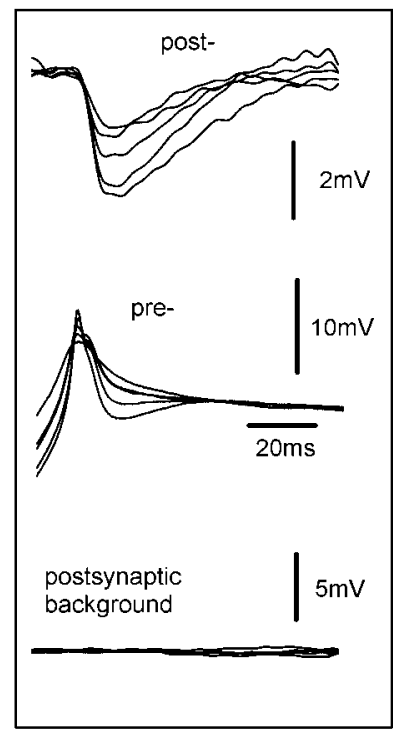

B

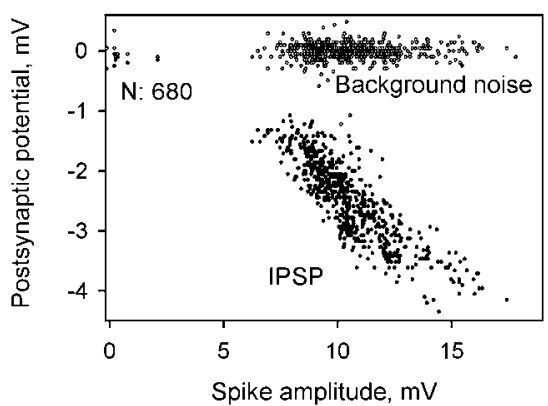

C

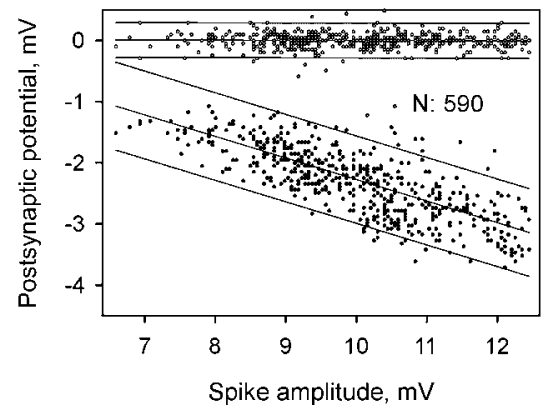

D

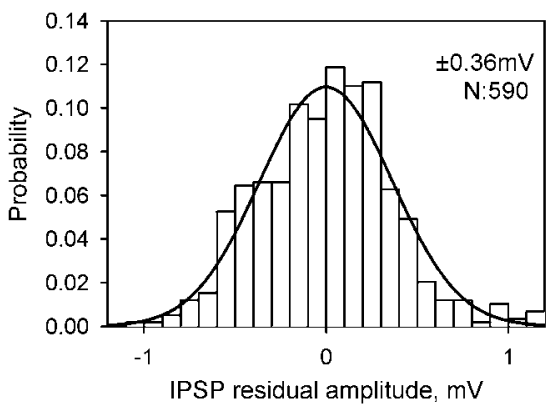

E

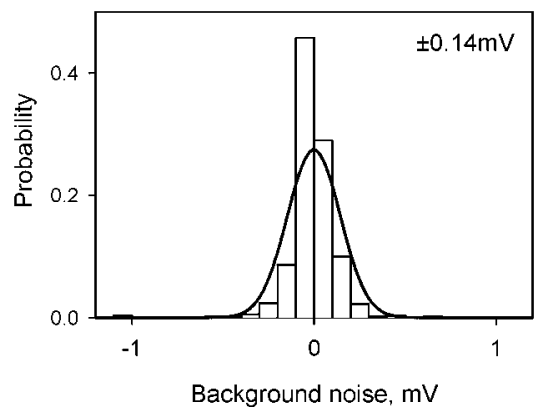

Figure 6. Transmission at an inhibitory synapse between two L-neurons when background noise was reduced. $A$, Overlaid recordings of five IPSPs (top traces) in response to rebound spikes of different amplitudes (middle traces). The background noise recorded along with each IPSP is shown on the bottom traces. $B$, Plot of IPSP amplitude against presynaptic spike amplitude for 680 IPSPs measured over 20 min. A measurement of background noise accompanied each IPSP recorded. $C$, Data for the linear part of the transfer curve in $B$, with regression lines and $95 \%$ prediction intervals. $D$, Distribution of IPSP residuals for the regression line drawn in $C$. The data had an SD of $\pm 0.36 \mathrm{mV}$, and the bell-shaped line is a normal distribution with this SD. $E$, Distribution of background noise measurements for the data in $C$. The line plots the best-fitting normal distribution for this data (SD, $\pm 0.14 \mathrm{mV}$ ).

amplitudes of spike if they differed by $\sim 1.5 \mathrm{mV}$. Dividing this value by the linear gain of the synapse (0.63) gives a difference of $2.4 \mathrm{mV}$ in the amplitudes of presynaptic spikes that can be discriminated. If background noise is subtracted, the performance of the synapse improves slightly to give discriminations of $1.2 \mathrm{mV}$ in IPSP amplitudes or $1.9 \mathrm{mV}$ in spike amplitudes. For this synapse, IPSPs in the linear part of the transfer function spanned a range of $6.5 \mathrm{mV}$, so the number of signal levels that could be transmitted at $80 \%$ reliability was just greater than four with background noise $(6.5 / 1.5 \mathrm{mV})$, or $\sim 5.5$ without background noise $(6.5 / 1.2 \mathrm{mV})$.

For this relatively high-gain synapse, variability in IPSP amplitude is attributable partly to variability within the operation of the connection itself, and partly to background noise originating in other input synapses to the postsynaptic neuron. Therefore, background noise was reduced in some subsequent experiments either by interfering with the normal operation of the ocellus or by increasing illumination.

\section{Transmission with background noise reduced}

Because the major source of synaptic input to an L-neuron is from photoreceptors in the ocellar retina, background noise should be reduced if synaptic transmission within the retina is blocked. This can be done by bathing the ocellar retina with cobalt (Wilson, 1978c; Simmons and Hardie, 1988), but it often takes 40 min for cobalt to have a significant effect on transmission in the retina, which made this technique impractical. However, I found that gently tearing the ocellus could reduce background noise substantially compared with preparations in which it was undamaged, although quite large responses by L-neurons to light stimuli persisted (mean background noise, $0.14 \pm 0.09 \mathrm{mV} ; n=$ 9, in torn preparations; $0.34 \pm 0.08 \mathrm{mV} ; n=8$, in preparations with undamaged ocelli). A possible explanation is that damaging the ocellus might cause photoreceptors to become coupled electrically to one another. Only one of the torn preparations produced IPSPs as large as $10 \mathrm{mV}$, and many produced very small IPSPs, but three produced IPSPs $>5 \mathrm{mV}$ in amplitude, and five of the remaining six produced IPSPs $>3 \mathrm{mV}$. Mean synaptic gain was only slightly lower in the preparations with torn ocellar sheaths $(-0.35 \pm 0.18$ vs $-0.37 \pm 0.16)$, indicating that, in the best preparations, damage to the ocellus did not interfere with the operation of the inhibitory connections between L-neurons. Results from these preparations (Figs. 6-8) were similar in nature to those obtained from the high-gain synapse described above.

In the experiment illustrated by Figures 6 and 7, the number of IPSPs collected from the linear part of the synaptic transfer curve was maximized by eliciting most spikes in the range of amplitudes between 7 and $12.5 \mathrm{mV}$. Recordings of presynaptic spikes, IPSPs, and background noise are shown in Figure $6 A$. Variation in spike shape was particularly marked in this experiment, but no effect of this was found on IPSP shape or size, emphasizing the speed with which transmission adapts at this synapse. Measurements of the amplitudes of IPSPs and background noise are plotted in Figure $6 B$. Over the linear range of the transfer curve (Fig. 6C), data were fitted by a linear regression with a slope of $-0.35\left(R^{2}=\right.$ 0.59 ). Residuals of individual IPSPs had an SD of $\pm 0.36 \mathrm{mV}$ from the regression line and gave a slightly flatter than normal distribution (Fig. 5D; kurtosis, 0.35; K-Sd, 0.04; $p=0.04$ ). Background noise had a significantly smaller scatter $(\mathrm{SD}, \pm 0.14 \mathrm{mV})$ and was 
A
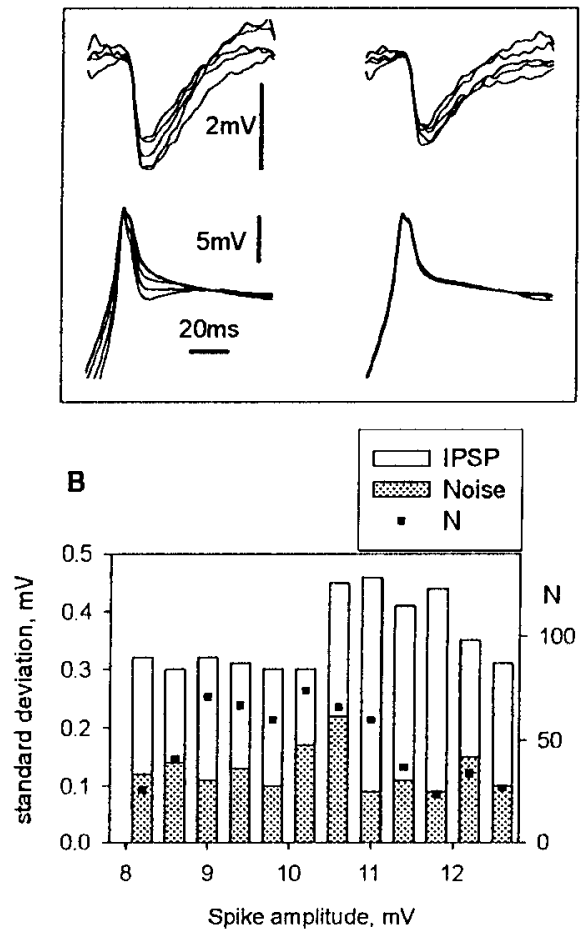

C

Spikes: 9.6 to $10.0 \mathrm{mV}$

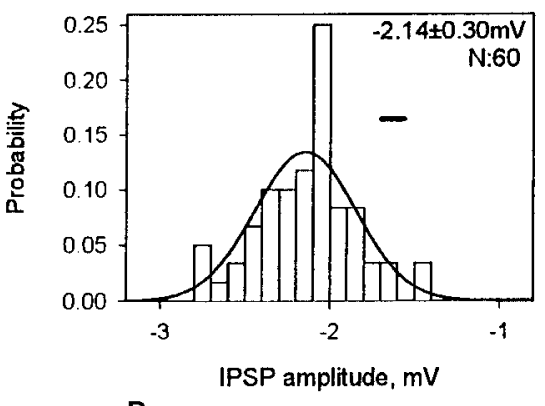

D

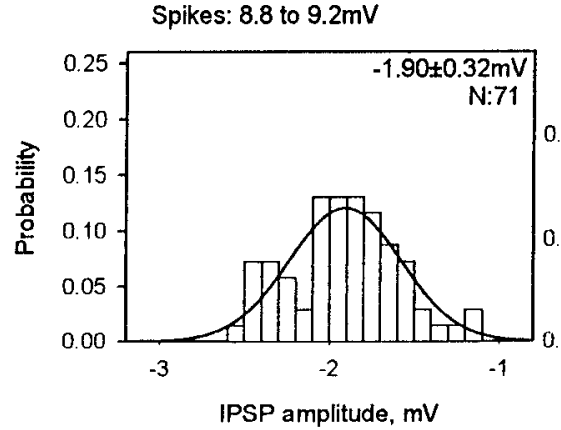

E

Background noise

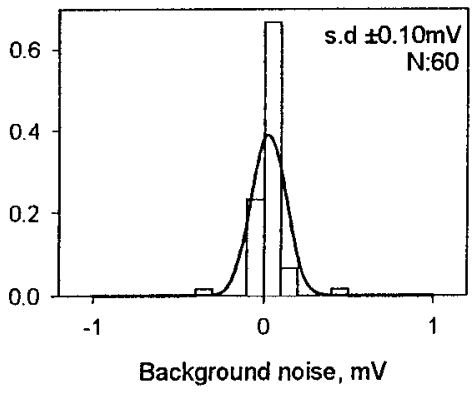

F

IPSPS: 2.1 to $2.3 \mathrm{mV}$

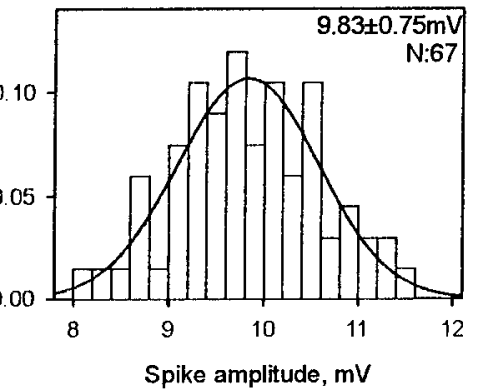

Figure 7. IPSPs mediated by particular amplitudes of presynaptic spikes, from the experiment shown in Figure 6 . $A$, Intracellular recordings of five overlaid IPSPs for two different presynaptic spike amplitudes. $B$, Histograms to show IPSP SD and background noise SD for presynaptic spikes of different amplitudes. The number of data points for each presynaptic spike amplitude is given, and data were collected over spikes that varied in amplitude over a range of $0.4 \mathrm{mV}$. $C, D$, distribution of IPSP amplitudes for spikes that varied between 9.6 and $10.0 \mathrm{mV}(C)$ or 8.8 and $9.2 \mathrm{mV}(D)$. The mean and SD of IPSP amplitude are given for each histogram, together with the best-fitting normal distribution. The horizontal line in $C$ indicates the range of IPSP amplitudes on the scale of the horizontal axis that would be elicited by a change in spike amplitude of $0.4 \mathrm{mV}$ if the relationship between spike and IPSP amplitudes were linear and noise-free. E, Histogram of background noise amplitudes and the best-fitting normal distribution for the IPSP in C. F, Distribution of spike amplitudes that mediated IPSPs between 2.1 and $2.3 \mathrm{mV}$ in amplitude, together with the best-fitting normal distribution.

more strongly peaked than a normal distribution (Fig. $5 E$; kurtosis, $18.8 ; K$-Sd, 0.16; $p<0.01)$.

As described for the high-gain synapse in Figure 5, IPSP amplitude varies for a particular amplitude of spike (Fig. 7A), and this variation is consistently greater than the background noise (Fig. $7 B$ ). In Figure $7 B$, each group of IPSPs was mediated by spikes within a $0.4 \mathrm{mV}$ range of amplitudes (equivalent to a 0.14 $\mathrm{mV}$ change in IPSP amplitude; Fig. $7 C$, short horizontal line). For each spike amplitude, IPSPs had SDs between \pm 0.3 and $0.46 \mathrm{mV}$, and the corresponding background noise was consistently less, between \pm 0.08 and $0.22 \mathrm{mV}$ (Fig. $7 B$ ). Samples of two distributions of IPSP amplitudes are plotted in Figure 7, $C$ and $D$. They both had slightly flatter shapes than normal distributions (Fig. $7 C$; kurtosis, 0.26; K-Sd, 0.1; $p=0.073$; Fig. 7D; kurtosis, -0.43 ; $\mathrm{K}-\mathrm{Sd}, 0.08 ; p=0.31)$. Background noise was strongly peaked near $0 \mathrm{mV}$ (Fig. 7E). The distribution of spike amplitudes that elicited IPSPs within a $0.2 \mathrm{mV}$ range was normal (Fig. $7 F$; K-Sd, $0.06 ; p=$ $0.74)$ with an average $\mathrm{SD}$ of $\pm 0.85 \mathrm{mV}$ ( $n=5$; range, \pm 0.71 to $\pm 1.00 \mathrm{mV}$ ).

The IPSPs at this synapse had an SD of $0.36 \mathrm{mV}$ (Figs. 6D, 7B), and background noise was $0.14 \mathrm{mV}$, so that the SD attributable to synaptic transfer was $\sim 0.33 \mathrm{mV}$ (square root of $0.36^{2}-0.14^{2}$ ). For discrimination with $80 \%$ reliability, two IPSPs would need to differ by $0.72 \mathrm{mV}$ with background noise or by $0.66 \mathrm{mV}$ without it, equivalent to differences in the amplitudes of two spikes of 2.1 and $1.9 \mathrm{mV}$. The synapse had an operating range spanning $10 \mathrm{mV}$ in spike amplitudes (or $3.5 \mathrm{mV}$ in IPSP amplitudes), which translates to approximately five signal levels (5.0 with background noise or 5.3 without it).

The lowest level of background noise recorded in this study was $\pm 0.07 \mathrm{mV}$, in an experiment in which the ocellus was torn (Fig. 8). Recordings of spikes and IPSPs from this experiment are shown in Figure $8 A$, and the synaptic transfer curve together with background noise are plotted in Figure $8 B$. The SD of IPSP amplitudes for a particular presynaptic spike amplitude was consistently greater than background noise in all parts of the transfer curve, and the SD of IPSP amplitude was $\pm 0.12 \mathrm{mV}$. Because of the relatively low background noise in this experiment, small IPSPs elicited by very small presynaptic rebound responses could be seen in intracellular recordings. The smallest presynaptic potential in Figure $8 A$ depolarized the neuron to $2 \mathrm{mV}$ from dark resting potential and elicited a small IPSP, $<0.1 \mathrm{mV}$ in the postsynaptic neuron. For 14 spikes up to $2 \mathrm{mV}$ in amplitude, 10 elicited clear IPSPs, and 3 of these are shown superimposed in Figure $8 C$ (second trace, arrows). In the remaining 4, no IPSP was apparent (two overlapping records; Fig. 8C, top trace), but it was impossible with certainty to determine the smallest amplitude of IPSP elicited. These observations indicate that the threshold for transmitter release at this synapse was below or at the dark resting potential of the presynaptic neuron, and that the smallest size of IPSP that could be elicited was $<0.1 \mathrm{mV}$. For slightly larger presynaptic depolarizing potentials, IPSP amplitude clearly increased in a graded manner but varied from trial to trial (Fig. 8D,E). 
A

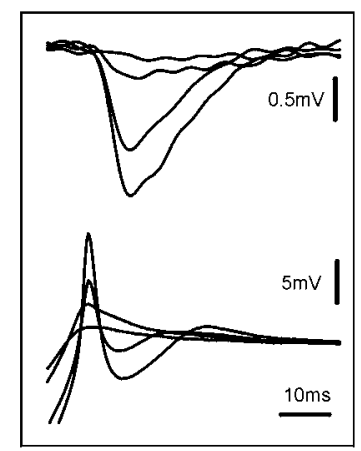

B

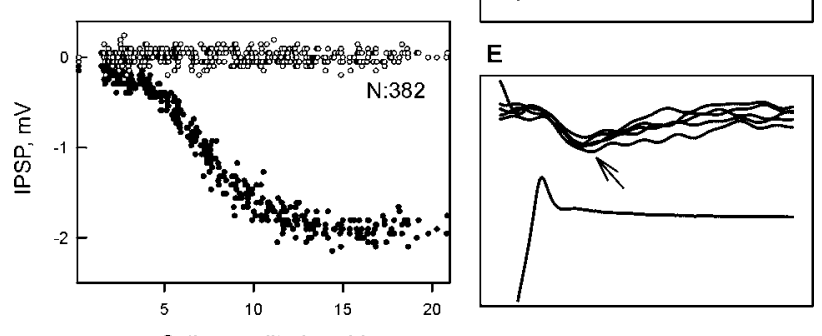

Spike amplitude, $\mathrm{mV}$

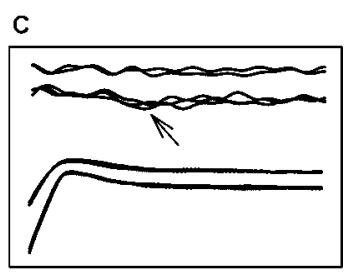

D

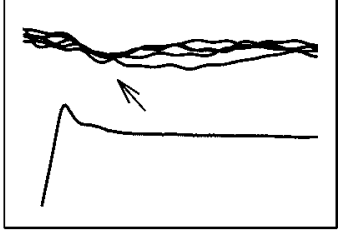

E
Figure 8. Transmission at a synapse where small IPSPs were recorded. $A$, Overlaid recordings of four different spike amplitudes (bottom traces) and the IPSPs they mediated (top traces). $B$, Transfer curve for the synapse. Background noise was $\pm 0.07 \mathrm{mV}$, and the SD of IPSP residuals for spikes between 5 and $10 \mathrm{mV}$ was $\pm 0.12 \mathrm{mV}$. $C$, Intracellular recordings of IPSPs (top two pairs of traces) produced by rebound spikes $2 \mathrm{mV}$ in amplitude (bottom two traces). No IPSPs were apparent in the top pair of traces, but an IPSP $\sim 0.1 \mathrm{mV}$ in amplitude is clear in each of the second pair of traces (arrow). D, E, Arrows indicate IPSPs mediated by spikes of $4(D)$ or $5(E) \mathrm{mV}$ in amplitude.

Data from all synapses that were analyzed in detail are given in Table 1. Preparations with torn ocelli showed significantly less variation both in background noise and in IPSP amplitude than preparations with undamaged ocelli (Mann-Whitney tests, background noise, $p<0.001$; IPSP variation, $p=0.016)$. In all preparations, variation in IPSP amplitude was greater than background noise: on average, for undamaged ocelli synaptic SD was $0.47 \mathrm{mV}$, and for damaged ocelli synaptic SD was $0.31 \mathrm{mV}$. The minimum difference between two spike amplitudes that could be resolved at $80 \%$ reliability was almost always $\sim 2 \mathrm{mV}$. Although many other parameters of transmission, including gain and maximum IPSP amplitude, varied considerably from preparation to preparation, they were consistent and stable within each preparation that yielded good, long-term recordings.

\section{Effects of illumination on IPSPs and on background noise}

Illuminating an ocellus caused a sustained hyperpolarizing potential and a change in background noise, which increased relative to dark level for dim illumination but then decreased as light intensity increased (Simmons, 1993). The amplitudes of IPSPs (relative to current resting potential) decreased, largely because of the increase in L-neuron conductance arising from increased input from photoreceptors (Fig. 9).

The intracellular recordings in Figure 9, $A$ and $B$ (undamaged ocellus) each show three IPSPs from the saturated part of the transfer curve. In the dark (Fig. 9A), the postsynaptic neuron had a relatively high level of background noise, $\pm 0.35 \mathrm{mV}$; the mean amplitude of IPSPs was $-3.6 \pm 0.69 \mathrm{mV}(n=170)$. Illumination (Fig. $9 B ; \sim 2 \mathrm{~mW} / \mathrm{cm}^{2}$ at the ocellus) hyperpolarized the neuron by $8 \mathrm{mV}$, decreased background noise to $\pm 0.19 \mathrm{mV}$, and changed the IPSP amplitude to $-1.4 \pm 0.44 \mathrm{mV}(n=76)$.

Measurements from the linear part of the transfer curves in another undamaged preparation are shown in Figure 9, $C$ and $D$. In the dark, the regression line for the linear part of the synaptic transfer curve had a slope of $-0.38 \mathrm{mV}$, and the IPSP had a maximum amplitude of $-6 \mathrm{mV}$. Illumination, which hyperpolarized the L-neuron by a steady $7 \mathrm{mV}$ from dark resting potential after $5 \mathrm{~min}$, reduced the slope to -0.10 and the maximum IPSP amplitude from -6 to $-2 \mathrm{mV}$. At the same time, IPSP variability decreased: residuals from the regression line had an SD of \pm 0.65 $\mathrm{mV}$ in the dark and $\pm 0.31 \mathrm{mV}$ in the light. Background noise decreased from \pm 0.38 to $\pm 0.19 \mathrm{mV}$.

\section{Variation in IPSPs at different output synapses from a single L-neuron}

In three experiments, IPSPs in two different postsynaptic neurons were recorded at the same time as the spikes that mediated them, and in two of the experiments recordings were sufficiently stable to plot synaptic transfer curves and analyze the distributions of IPSPs. For each spike in the recording, the residual of the IPSP from its regression in one neuron was plotted against the corresponding residual in the second postsynaptic neuron (Fig. 10). There was no significant correlation between the residuals for the IPSPs in the two neurons; the best fit regression line had an $R^{2}$ of 0.008. Background noise in the two neurons was also not well correlated: the regression for this had an $R^{2}$ of 0.019 . This indicates that each IPSP varies in amplitude independently of the other, so that variation is localized to particular synaptic terminals.

\section{DISCUSSION}

\section{Synaptic performance}

The graded relation between presynaptic and postsynaptic potentials was first demonstrated for synapses that relay large spikes (Katz and Miledi, 1967), and it is exploited to transmit signal levels directly and rapidly at synapses where the presynaptic neuron does not produce all-or-none spikes. The smallest change in presynaptic potential that can be transmitted reliably is a measure of resolution, and, at the inhibitory synapses between L-neurons, unreliability in transmission limits the number of discrete signal levels they can convey to $\sim 5$ at best. In contrast, in fly compound eyes recordings of responses to light stimuli from photoreceptors or second-order large monopolar cells (LMCs) (Laughlin et al., 1987; Juusola et al., 1995) indicate a performance an order of magnitude better, enabling LMCs to resolve $2 \%$ modulations in light intensity (Laughlin, 1989). In daylight, the photoreceptor to LMC synapse contributes $50-70 \%$ of the noise in the $\mathrm{LMC}$, the remainder originating in photoreceptors (Laughlin et al., 1987). The level of synaptic noise is, therefore, similar at synapses between L-neurons and between photoreceptors and LMCs. The superior performance of the latter is due to a greater operating range. These two types of synapses might represent standards of performance at different ends of a spectrum for graded potential synapses, perhaps related to their different roles. All the information the visual system obtains passes through the photoreceptor to LMC synapse, so any loss of information here would degrade the ability of the fly to see and react to objects. The function of the inhibitory synapses between L-neurons is not so obvious; they will function to reduce the 


\begin{tabular}{|c|c|c|c|c|c|c|}
\hline & $\begin{array}{l}\text { IPSP variation } \\
\text { [mean (range), } \\
\mathrm{mV}]\end{array}$ & $\begin{array}{l}\text { Background noise } \\
\text { [mean (range), } \\
\mathrm{mV}]\end{array}$ & $\begin{array}{l}\text { Synaptic noise } \\
\text { [mean (range), } \\
\mathrm{mV}]\end{array}$ & $\begin{array}{l}\text { Gain [mean } \\
\text { (range)] }\end{array}$ & $\begin{array}{l}\text { Spike resolu- } \\
\text { tion [mean } \\
\text { (range), mV] }\end{array}$ & $\begin{array}{l}\text { IPSPs } \\
{[\text { mean }} \\
\text { (range)] }\end{array}$ \\
\hline Intact ocellus $(n=8)$ & $\begin{array}{l}0.58 \\
(0.5-1.3)\end{array}$ & $\begin{array}{l}0.34 \\
(0.29-0.54)\end{array}$ & $\begin{array}{l}0.47 \\
(0.43-1.2)\end{array}$ & $\begin{array}{l}-0.37 \\
(-0.24 \text { to }-0.63)\end{array}$ & $\begin{array}{l}2.5 \\
(1.9-5.3)\end{array}$ & $\begin{array}{l}631 \\
(228-2060)\end{array}$ \\
\hline Torn ocellus $(n=9)$ & $\begin{array}{l}0.34 \\
(0.24-0.88)\end{array}$ & $\begin{array}{l}0.14 \\
(0.07-0.34)\end{array}$ & $\begin{array}{l}0.31 \\
(0.21-0.81)\end{array}$ & $\begin{array}{l}-0.35 \\
(0.20 \text { to }-0.60)\end{array}$ & $\begin{array}{l}1.8 \\
(1.6-6.3)\end{array}$ & $\begin{array}{l}385 \\
(154-680)\end{array}$ \\
\hline
\end{tabular}

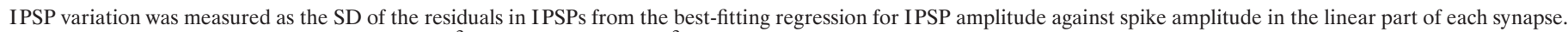

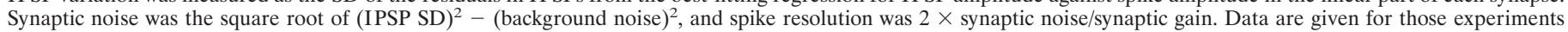
in which synaptic gain was $>0.2$ and the maximum IPSPs were $\geq 4 \mathrm{mV}$.
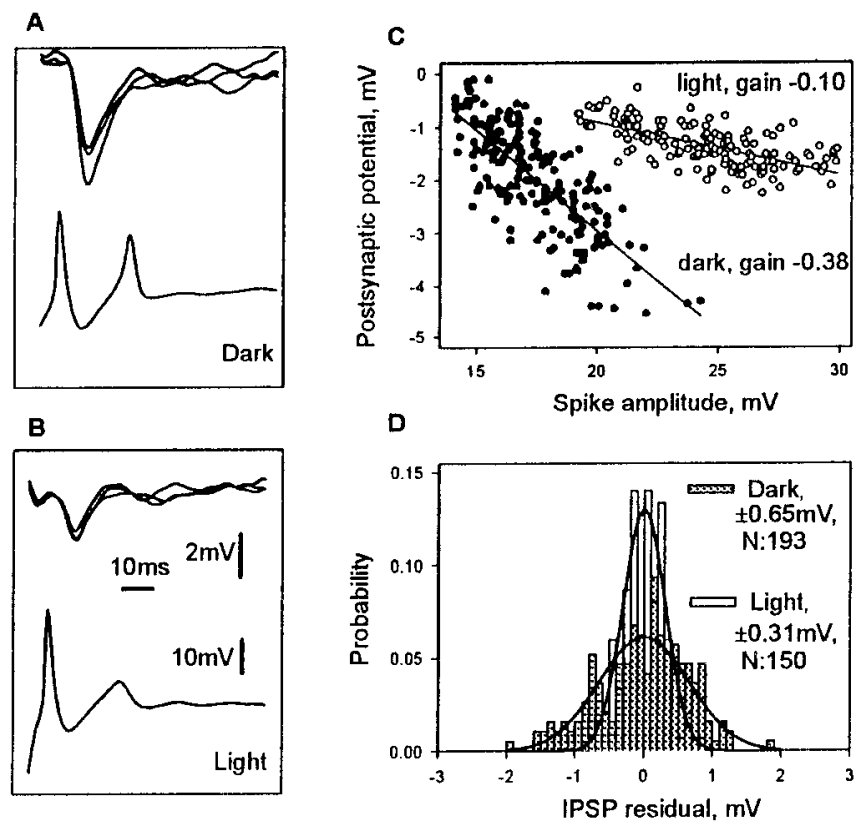

Figure 9. Effects of illumination on transmission at an inhibitory synapse between two L-neurons. $A, B$, Recordings of IPSPs (top traces, three IPSPs overlaid) and spikes (bottom trace, single spike) from the saturated part of the transfer curve recorded in darkness $(A)$ and in bright illumination $(B) . C$, Linear parts of the transfer curve in another preparation under two different conditions of illumination. A linear regression line is drawn for each set of data. $D$, Histograms of the distribution of IPSP residuals for the regression lines drawn in $C$ together with the best-fitting normal distributions.

likelihood that a spike in a postsynaptic neuron will immediately follow a spike in a presynaptic neuron, suggesting that it is important that excitation in the three L1-3 neurons after a sudden decrease in light should be short-lived, perhaps marking precisely the time of a sudden decrease in illumination.

Synapses work in diverse ways (Walmsley et al., 1998), and arthropod visual systems offer a good opportunity to relate differences in performance to differences in function. The inhibitory synapses between L-neurons are low in gain and resolution, transmitting phasically. Synaptic gain here is usually $<0.5$, in comparison with 20 at output synapses from ocellar photoreceptors (Simmons, 1995), which makes L-neurons extremely sensitive to changes in light (Wilson, 1978a). A high gain is a important for improving signal-to-noise ratio (Laughlin et al., 1987) and is characteristic of synapses from photoreceptors: it is 6 in the fly compound eye (Laughlin et al., 1987), 2.5 for barnacle ocelli (Hayashi et al., 1985), and perhaps as great as 100 for outputs from photoreceptors in the vertebrate retina (Shiells, 1995). Else-

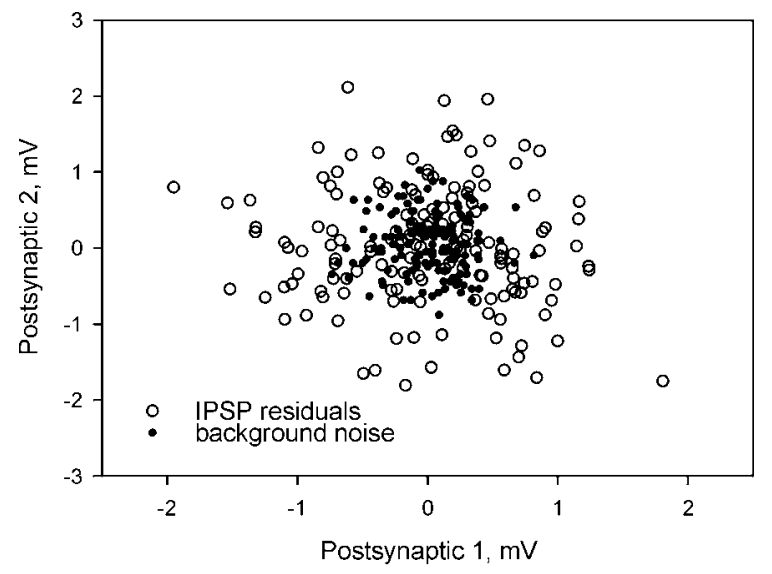

Figure 10. Lack of correlation between IPSPs mediated by the same presynaptic L-neuron in two different target L-neurons. Measurements were taken over the linear region of the transfer curve for each synapse and for each spike; the residuals of the two IPSPs from their linear regression lines are plotted against each other. There was little correlation between the amplitudes of the residuals for the two IPSPs (regression $R^{2}=0.008$ ). Background noise in the two neurons was also not significantly correlated $\left(R^{2}=0.019\right)$. The scatter in IPSP amplitudes between the two neurons was larger than would be expected from background noise alone.

where, synaptic gain is lower: for example, $\sim 1$ at outputs from nonspiking neurons in locust thoracic ganglia (Siegler, 1985), between motion-sensitive neurons in the locust brain (Rind, 1984), and between a proprioceptor and a motor neuron in the crab (Blight and Llinás, 1980). A consequence of high gain is that a synapse only operates over a narrow range of presynaptic potentials, so that adaptation is necessary to remove any sustained signal proportional to mean intensity that the photoreceptor produces (Laughlin and Hardie, 1978; Hayashi et al., 1985, Simmons, 1995).

The synapse from an L-neuron onto a third-order neuron has a gain of $\sim 1$ (Simmons, 1981, 1993). This is lower than the synapse from a photoreceptor to an L-neuron (Simmons, 1995), which is associated with the task the third-order neuron performs in integrating postsynaptic potentials from the ocellar pathway with those from wind-sensitive hairs (Simmons, 1980). This excitatory synapse transmits tonically without decrement or adaptation. However, its threshold for transmission is only $5 \mathrm{mV}$ hyperpolarized from dark resting potential, so the operating range of the synapse is sixfold less than the range of voltages available to an L-neuron for signaling increases in light intensity. This feature has also been found for the second synapses in the ocellar pathways of barnacles (Stuart and Oertel, 1978) and cockroaches (Mizunami and Tateda, 1988). If it also occurs at output synapses 
from compound eye LMCs, it will severely limit the number of signal levels that can be passed on to third-order neurons in the medulla.

\section{Control of transmitter release}

For a synapse to transmit graded potentials with good resolution, it requires both a small quantal amplitude and a mechanism that ensures the rate of release is accurately regulated by presynaptic potential. The smallest responses that could be distinguished from background noise when a presynaptic L-neuron was stimulated were $<0.1 \mathrm{mV}$. This means that individual quanta of neurotransmitter generate responses $<0.1 \mathrm{mV}$, which is smaller than the quantal size for synapses from spiking neurons in the insect CNS. Laurent and Sivaramakrishnan (1992) measured quantal amplitude at just $<0.3 \mathrm{mV}$ for synapses from locust thoracic local interneurons, with six quanta per spike on average; and Sosa and Blagburn (1995) measured quantal amplitudes at $0.2-0.27 \mathrm{mV}$ for synapses from cockroach cercal mechanoreceptors. In leg motor neurons of a crab, Blight and Llinás (1980) suggested that small $0.1 \mathrm{mV}$ jitters in potential could be responses to individual quanta of transmitter released by a nonimpulsive mechanoreceptor. At the inhibitory synapses between L-neurons, a $5 \mathrm{mV}$ IPSP would consist $\geq 50$ quanta if the quantal amplitude of the synapse is $<0.1 \mathrm{mV}$. The number of signal levels that can be transmitted, however, is 5- or 10-fold fewer than this, which emphasises that the mechanism coupling presynaptic voltage to transmitter release is a major source of unreliability in signal transfer.

Each inhibitory synapse between a pair of L1 -3 neurons is composed of $\sim 50$ discrete contacts, each with its own presynaptic density and population of synaptic vesicles (Littlewood and Simmons, 1992). The lack of correlation between deviations in IPSP amplitudes at two outputs from a single L-neuron implies that different discrete synaptic zones in a neuron can act independently, as has been demonstrated a number of times previously, for example, in leech ganglia (Muller and Nicholls, 1974), for local spiking neurons in the locust thoracic ganglia (Laurent and Sivaramakrishnan, 1992), and for neurons in Aplysia (Gardner, 1991). The number of discrete synapses at a connection between two L-neurons is of the same order of magnitude as the number of discrete events underlying an IPSP: a $5 \mathrm{mV}$ IPSP could be composed of 50 events of $0.1 \mathrm{mV}$. The SD of the IPSPs is usually between 0.4 and $0.5 \mathrm{mV}$, or four or five discrete events. In a Poisson process, the variance of a number of events is equal to the mean; consequently, if transmitter release is a Poisson process, an SD of 5 events would predict a mean of 25 events, a number also of the same order of magnitude as the number of discrete anatomical contacts.

If presynaptic potential is related in a simple way to the probability of release, we would expect to find that when the mean amplitude of a postsynaptic potential increases, its SD also increases. This was not found at the inhibitory synapses between L-neurons: the SD of IPSP amplitude was constant in different parts of the transfer curve, indicating there is unlikely to be a uniform increase in the probability of the release of individual vesicles at synaptic contacts between two L-neurons. Instead, presynaptic potential might somehow influence the availability of vesicles for release, or the number of discrete contacts that are active. This has been proposed before for a synapse that conveys graded potentials between hair cells and large afferent auditory fibers of the goldfish ear (Furukawa et al., 1978, 1982), where increases and decreases in the intensity of sound are encoded as a graded receptor potential in the hair cells and as summed
EPSPs in their postsynaptic neurons. The differences in EPSP amplitude after increases or decreases in sound were better described as changes in the binomial parameter $n$, which is normally considered to be a measure of the amount of transmitter available for release, than changes in $p$, a measure of the probability of release of each vesicle. Furukawa et al. $(1978,1982)$ suggested that each synaptic site within a single hair cell has a different voltage sensitivity for release and a different rate of vesicle replenishment. For the fly compound eye lamina synapse, Laughlin and de Ruyter van Steveninck (1996) have also briefly proposed that each of the 220 distinct contacts (Nicol and Meinertzhagen, 1982) acts independently and has a distinct threshold voltage for release of a single vesicle. The same type of scheme can also operate for spiking neurons, such as tonic motoneurons in lobsters, where a single neuron makes output synapses that release transmitter at different rates, and an increase in spike frequency recruits additional contacts rather than increasing activity in all synaptic sites uniformly (Quigley et al., 1999). Clearly, a key step in improving our understanding of the mechanisms of graded synaptic transmission will be to elucidate how membrane potential influences the rate at which synaptic vesicles are released at individual synaptic contacts.

\section{REFERENCES}

Ammermüller J (1986) Passive cable properties of locust ocellar L-neurones. J Comp Physiol [A] 158:339-344.

Ammermüller J, Zettler F (1986) Time- and voltage-dependent currents in locust ocellar L-neurones. J Comp Physiol [A] 159:363-376.

Angstadt JD, Calabrese RL (1991) Calcium currents and graded synaptic transmission between heart interneurons of the leech. J Neurosci 11:746-759.

Ashmore JF, Copenhagen DR (1983) An analysis of transmission from cones to hyperpolarising bipolar cells in the retina of the turtle. J Physiol (Lond) 340:569-597.

Blight AR, Llinás R (1980) The non-impulsive stretch-receptor complex of the crab: a study of depolarization-release coupling at a tonic sensorimotor synapse. Philos Trans R Soc Lond B Biol Sci 290:219-276.

Boyd IA, Martin AR (1956) The end-plate potential in mammalian muscle. J Physiol (Lond) 132:74-91.

Burrows M, Siegler MVS (1978) Graded synaptic transmission between local interneurones and motoneurones in the metathoracic ganglion of the locust. J Physiol (Lond) 285:231-255.

de Ruyter van Steveninck RR, Laughlin SB (1996) The rate of information transfer at graded-potential synapses. Nature 379:642-645.

del Castillo J, Katz B (1954) Quantal components of the end-plate potential. J Physiol (Lond) 124:560-573.

Furukawa T, Hayashida Y, Matsuura S (1978) Quantal analysis of the size of the excitatory post-synaptic potentials at synapses between hair cells and afferent nerve fibres in goldfish. J Physiol (Lond) 276:211-226.

Furukawa T, Kuno M, Matsuura S (1982) Quantal analysis of a decremental response at hair cell-afferent fibre synapses in goldfish sacculus. J Physiol (Lond) 322:181-195.

Gardner D (1991) Presynaptic transmitter release is specified by postsynaptic neurons of Aplysia buccal ganglia. J Neurophysiol 66:2150-2154.

Goodman CS (1976) Anatomy of the ocellar interneurones of acridid grasshoppers. I. The large interneurones. Cell Tissue Res 175:467-492.

Goodman LJ, Mobbs PG, Kirkham BJ (1979) The fine structure of the ocellus of Schistocerca gregaria. The neural organisation of the synaptic plexus. Cell Tissue Res 196:487-510.

Gulyás AI, Miles R, Sík A, Tóth K, Freund TF (1993) Hippocampal pyramidal cells excite inhibitory neurons through a single release site. Nature 366:683-687.

Hayashi JH, Moore JW, Stuart AE (1985) Adaptation in the inputoutput relation of the synapse made by the barnacle photoreceptor. J Physiol (Lond) 368:175-195.

Johnson EW, Wernig A (1971) The binomial nature of transmitter release at the crayfish neuromuscular junction. J Physiol (Lond) 218:757-767.

Juusola M, Uusitalo RO, Weckström M (1995) Transfer of graded po- 
tentials at the photoreceptor-interneuron synapse. J Gen Physiol 105:117-148.

Katz B, Miledi R (1967) A study of synaptic transmission in the absence of nerve impulses. J Physiol (Lond) 192:407-436.

Korn H, Mallet A, Triller A, Faber D (1982) Transmission at a central synapse. II. Quantal description of release with a physical correlate for binomial n. J Neurophysiol 48:679-707.

Kuno M (1964) Quantal components of excitatory postsynaptic potentials in spinal motoneurones. J Physiol (Lond) 175:81-99.

Laughlin SB (1989) The reliability of single neurons and circuit design: a case study. In: The computing neuron (Durbin R, Miall C, Mitchison G, eds), pp 322-336. Wokingham, UK: Addison-Wesley.

Laughlin SB, de Ruyter van Steveninck RR (1996) Measurements of signal transfer and noise suggest a new model for graded transmission at an adapting retinal synapse. J Physiol (Lond) 494:P19.

Laughlin SB, Hardie RC (1978) Common strategies for light adaptation in the peripheral visual systems of fly and dragonfly. J Comp Physiol 128:319-340.

Laughlin SB, Howard J, Blakeslee B (1987) Synaptic limitations to contrast coding in the retina of the blowfly Calliphora. Proc R Soc Lond B Biol Sci 231:437-467.

Laurent G (1990) Voltage-depedent nonlinearities in the membrane of locust nonspiking local interneurons, and their significance for synaptic integration. J Neurosci 10:2268-2280.

Laurent G, Sivaramakrishnan A (1992) Single local interneurons in the locust make central synapses with different properties of release on distinct postsynaptic neurons. J Neurosci 12:2370-2380.

Lillywhite PG (1977) Single photon signals and transduction in an insect eye. J Comp Physiol 122:189-200.

Littlewood PMH, Simmons PJ (1992) Distribution and structure of identified tonic and phasic synapses between L-neurones in the locust ocellar tract. J Comp Neurol 325:493-513.

Manor Y, Nadim F, Abbott LF, Marder E (1997) Temporal dynamics of graded synaptic transmission in the lobster stomatogastric ganglion. J Neurosci 17:5610-5621.

Mizunami M, Tateda H (1988) Synaptic transmission between secondand third-order neurones of cockroach ocelli. J Exp Biol 140:557-561.

Muller KJ, Nicholls JG (1974) Different properties of synapses between a single sensory neurone and two different motor cell in the leech C.N.S. J Physiol (Lond) 238:357-369.

Nicol D, Meinertzhagen IA (1982) An analysis of the number and composition of synaptic populations formed by photoreceptors of the fly. J Comp Neurol 207:29-44.

Patterson JA, Goodman LJ (1974) Intracellular responses of receptor cells and second order cells of the ocelli of the locust Schistocerca gregaria. J Comp Physiol 95:237-250.

Quigley PA, Msghina M, Govind CK, Atwood HL (1999) Visible evidence for differences in synaptic effectiveness with activity-dependent vesicular uptake and release of FM1-43. J Neurophysiol 81:356-370.

Rieke F, Warland D, de Ruyter van Steveninck RR, Bialek W (1997) Spikes: exploring the neural code. Cambridge, MA: MIT.
Rind FC (1984) A chemical synapse between two motion-detecting neurones in the locust brain. J Exp Biol 110:143-167.

Rowell CHF, Reichert H (1986) Three descending interneurons reporting deviation from course in the locust. II. Physiology. J Comp Physiol [A] 158:775-794

Shiells R (1995) Photoreceptor-bipolar cell transmission. In: Neurobiology and clinical aspects of the outer retina (Djamgoz MA, Archer SN, Vallerga S, eds), pp 297-324, London: Chapman and Hall.

Siegler MVS (1985) Nonspiking interneurons and motor control in insects. Adv Insect Physiol 18:249-304.

Simmons PJ (1980) A locust wind and ocellar brain neurone. J Exp Biol 85:281-294.

Simmons PJ (1981) Synaptic transmission between second- and thirdorder neurones of a locust ocellus. J Comp Physiol 145:265-276.

Simmons PJ (1982) Transmission mediated with and without spikes at connexions between large second-order neurones of locust ocelli. J Comp Physiol 147:401-414.

Simmons PJ (1985) Postsynaptic potentials of limited duration in visual neurones of a locust. J Exp Biol 117:193-213.

Simmons PJ (1993) Adaptation and responses to changes in illumination by second- and third-order neurones of locust ocelli. J Comp Physiol [A] 173:635-648.

Simmons PJ (1995) The transfer of signals from photoreceptor cells to large second-order neurones in the ocellar system of the locust Locusta migratoria. J Exp Biol 198:537-549.

Simmons PJ, Hardie RC (1988) Evidence that histamine is a neurotransmitter of photoreceptors in the locust ocellus. J Exp Biol 138:129-142.

Snyder AW, Laughlin SB, Stavenga DG (1977) Information capacity of eyes. Vision Res 17:1163-1175.

Sosa MA, Blagburn JM (1995) Competitive interactions between supernumerary and normal sensory neurons in the cockroach are mediated through a change in quantal content and not quantal size. J Neurophysiol 74:1573-1582.

Stuart AE, Oertel D (1978) Neuronal properties underlying processing of visual information in the barnacle. Nature 275:287-290.

Theunissen F, Roddey JC, Stufflebeam S, Clague H, Miller JP (1996) Information theoretic analysis of dynamical encoding by four identified primary sensory interneurons in the cricket cercal system. J Neurophysiol 74:1345-1364.

Walmsley B, Alvarez FJ, Fyffe REW (1998) Diversity of structure and function at mammalian central synapses. Trends Neurosci 21:81-88.

Wilson M (1978a) The functional organisation of locust ocelli. J Comp Physiol 124:297-316.

Wilson M (1978b) Generation of graded potential signals in the second order cells of locust ocellus. J Comp Physiol 124:317-331.

Wilson M (1978c) The origin and properties of discrete hyperpolarising potentials in the second order cells of locust ocellus. J Comp Physiol 128:347-358.

Zettler F, Järvilehto M (1973) Active and passive axonal propagation of non-spike signals in the retina of Calliphora. J Comp Physiol 85:89-104. 